\title{
Anti-CEA-CAR Autologous T Lymphocytes
}

National Cancer Institute

\section{Source}

National Cancer Institute. Anti-CEA-CAR Autologous T Lymphocytes. NCI Thesaurus.

Code C121784.

Autologous lymphocytes transduced with a retroviral vector encoding a chimeric antigen receptor (CAR) specific for the tumor-associated antigen human carcinoembryonic antigen (CEA), with potential immunostimulating and antineoplastic activities. Upon administration, the anti-CEA-CAR autologous T-lymphocytes target and bind to tumor cells expressing CEA, which results in the cytotoxic T-lymphocyte (CTL)-mediated cell killing of CEA-expressing tumor cells. CEA is overexpressed in various tumor cell types. 